\title{
Portfolio Optimization for Stock Market in Ghana Using Value-at-Risk (VaR)
}

\author{
Eric Kwame Austro Gozah ${ }^{1}$, Eric Neebo Wiah ${ }^{2,}$, Albert Buabeng ${ }^{2}$, Paul Yaw Addai Yeboah ${ }^{3}$ \\ ${ }^{1}$ Mathematics Department, Dambai College of Education, Dambai, Ghana \\ ${ }^{2}$ Department of Mathematical Sciences, Faculty of Engineering, University of Mines and Technology, Tarkwa, Ghana \\ ${ }^{3}$ Head, University Relations Office, University of Mines and Technology, Tarkwa, Ghana
}

\section{Email address:}

austro1979@yahoo.com (E. K. A. Gozah), enwiah@umat.edu.gh (E. N. Wiah), abuabeng@umat.edu.gh (A. Buabeng), pyeboah@umat.edu.gh (P. Y. A. Yeboah)

${ }^{*}$ Corresponding author

\section{To cite this article:}

Eric Kwame Austro Gozah, Eric Neebo Wiah, Albert Buabeng, Paul Yaw Addai Yeboah. Portfolio Optimization for Stock Market in Ghana Using Value-at-Risk (VaR). American Journal of Mathematical and Computer Modelling. Vol. 5, No. 3, 2020, pp. 61-69.

doi: $10.11648 /$ j.ajmcm.20200503.11

Received: June 10, 2020; Accepted: June 23, 2020; Published: July 6, 2020

\begin{abstract}
The study was conducted to identify the performing stocks as well as examine the portfolio optimization with associated Value at Risk (VaR) for some selected stocks on the Ghana Stock Exchange (GSE). A historical data of 15 companies categorized into Financial Stock Index (FSI) and Composite Index (CI) from 2000 to 2017 were obtained from Bank of Ghana (BoG), Ghana Stock Exchange (GSE) and Gold Coast Security (GCS). From the study, ETI, HFC, SIC, TOTAL, FML, UNIL and GOIL stocks were identified to be over performing on the Ghana Stock Exchange. Also, CAL, EBG, ALW, AYRTN, GOIL were identified as aggressive stocks; GCB, SCB, TOTAL, GGBL as defensive stocks; and ETI, HFC, SIC, FML, PZC, UNIL as inversely moving towards the market return. The optimal portfolio asset allocation, for the minimum VaR portfolio showed a marginal diversification in other stocks in the cases of FSI, but greater portion was invested in HFC. However, in the case of CI displayed no indication of diversification in the portfolio as $67.30 \%$ of investors invested in AYRTN and only $32.70 \%$ in the remaining securities. The study then proceeded to find the optimal portfolio with risk-free asset for both indexes. It was recommended that further study should extend the approaches used by considering Conditional Value at Risk (CVaR) as the VaR measure does not give any information about potential losses in the worst cases.
\end{abstract}

Keywords: Stock, Financial Stock Index, Composite Index, VaR, Portfolio, Optimization

\section{Introduction}

The borders of the financial markets expanded so that people in different parts of the world can invest in the markets of other countries. In this complex system, investors are concerned with the risk of their investments and it is their humble wish to construct portfolios that would take less risk and get more returns. With this understanding researchers have developed different models to calculate the risk of financial assets and use it in portfolio selection [8].

Financial institutions invest in a reliable risk measurement and management techniques to measure and control market, credit, liquidity and operational risks.

The question is; what is the challenge and prospect of the
Ghana Stock Exchange now? This question is relevant because at the end of 2004, Ghana Stock Exchange (GSE) was adjudged the world's best-performing market with a year return of 144 percent in US dollar terms, compared with 30 percent return by Morgan Stanley Capital International Global Index [10]. Research shows that Ghana has a potential for a vibrant capital raising activity in the future [16]. However, despite its improvement in 20 years of operation, GSE still has relatively small number of companies listed on the stock exchange (compared to other Africa countries like Kenyan, Namibia, Egypt, South Africa etc) even though in terms of indicators, it is one of the fastest growing Africa stock markets [12].

Although, there are several studies that have examined the performance of stock prices and assets returns using the 
Markowitz model measured by the variance of portfolio returns [2, 9, 11, 13, 14]. However, the variance is a symmetrical measure that does not take into consideration the direction of movement. This issue is addressed by finding alternative risk measures such as Value at Risk (VaR) to replace the variance. Moreover, there are no much study made on the study of portfolio optimisation using varied methods of Value-at-Risk at the Ghana Stock Exchange. Hence, the study is aimed at identifying the performing stocks as well as use Value-at-Risk to determine how the various stocks are responding in terms of optimisation. The study will as a result bring out a broader understanding of the associated risk factors of the stock on the Ghana Stock Exchange.

\section{Methodology}

DataStream is used to collect monthly and daily stock returns from January, 2000 until August 2017, which provides us with 258 monthly (1290) observations from six sectors. The data used were collected from Bank of Ghana (BoG), Ghana Stock Exchange (GSE) and Gold Coast Security (GCS). Seven stocks were selected at random from Financial Stock Index (FSI) and eight from the Composite Index (CI) based on the available time series data of returns on the stock market. The purpose of the choice of these specific sectors largely depend on the coverage of several levels of systematic risk $(\beta)$ calculated. Table 1 shows the Stocks considered in the study.

Table 1. Securities Considered.

\begin{tabular}{|c|c|c|c|c|c|}
\hline Sn & Stock & Initials & Sn & Stock & Initials \\
\hline \multicolumn{3}{|c|}{ Financial Stock Index } & \multicolumn{3}{|c|}{ Composite Index } \\
\hline 1 & Ecobank Transnational Inc & ETI & 1 & Aluworks Ltd & ALW \\
\hline 2 & HFC Bank & $\mathrm{HFC}$ & 2 & Ayrton Drug Manufacturing Ltd & AYRTN \\
\hline 3 & Star Insurance Company & SIC & 3 & GOIL & GOIL \\
\hline 4 & Ghana Commercial Bank & GCB & 4 & Fan Milk Limited & FML \\
\hline 5 & Ecobank & EBG & 5 & Guinness Ghana Breweries Ltd & GGBL \\
\hline 7 & Standard Chartered Bank & $\mathrm{SCB}$ & 7 & TOTAL & TOTAL \\
\hline 8 & & & 8 & Uniliver & UNIL \\
\hline
\end{tabular}

\subsection{Preliminary Analysis}

Jarque-Bera Test is a goodness-of-fit test which examines if the sample data have kurtosis and skewness like a normal distribution [7]. The test statistic is given by

$$
J B=T\left[\frac{b_{1}^{2}}{6}+\frac{\left(b_{2}-3\right)^{2}}{24}\right]
$$

where $b_{1}$ and $b_{2}$ are the sample skewness and kurtosis respectively. The Hypothesis is given by:

$$
\begin{aligned}
& H_{0}: \text { normality } \\
& H_{1} \text { : non-normality }
\end{aligned}
$$

\subsection{Stock Performance}

\subsubsection{Jensen Alpha Model}

The Jensen alpha ( $\alpha$ ), determines the performance of the stock to the market and it is expressed as Equation (2)

$$
\alpha=r_{p}-\left[r_{f}+\left(r_{m}-r_{f}\right) \beta_{p}\right]
$$

where

$$
\begin{aligned}
& r_{p}=\text { actual or realised returns of an asset } p \\
& r_{m}=\text { return of the market } \\
& r_{f}=\text { risk-free rate } \\
& \beta_{p}=\text { beta of the asset } p \\
& \left(r_{m}-r_{f}\right)=\text { risk premium } \\
& C_{0}=\text { assumed initial capital to be invested by the }
\end{aligned}
$$

\section{investor $=\mathrm{GHC} 1.00$}

\subsubsection{Sharpe Ratio}

The Sharpe Ratio examine the performance of an investment by adjusting for its risk [15]. The ratio measures the excess return (or risk premium) per unit of deviation in an investment asset as shown in Equation (3)

$$
S_{p}=\frac{E\left(r_{p}-r_{f}\right)}{\sigma_{p}}
$$

where $E\left(r_{p}-r_{f}\right)$ is the expected return of the excess of the asset return over the benchmark return, and $\sigma_{p}$ is the standard deviation of the asset excess return and.

\subsection{Portfolio Optimization}

\subsubsection{Portfolio Investment Problem Model}

Portfolio Investment problem model is a model design to aid investor take well informed investment decision at any point in time. Achievement of the objective function of the investor is characterised by two constraints (i) minimising risk given return and (ii) invest the capital the investor had at that moment, so that the amount invested on each asset sum up to $C_{0}$. The parameters of the problem are as follow:

$$
\begin{aligned}
& \mu=\text { expected return } \\
& \mu_{p}=\text { expected portfolio return } \\
& \theta=\text { portfolio } \\
& \overline{1}=\text { single asset } \\
& E\left(r_{p}\right)=\text { expected on the total portfolio return } \\
& \operatorname{VaR}_{\alpha}=\text { Value at Risk at confidence level }(1-\alpha)
\end{aligned}
$$




$$
\Sigma=\left(\begin{array}{ccc}
a_{11} & \cdots & a_{1 n} \\
\vdots & \ddots & \vdots \\
a_{m 1} & \cdots & a_{m n}
\end{array}\right)=\text { matrix of covariances of } r_{p}
$$

The constraint that must hold to minimise the risk factor or risk minimisation whiles maximising expected return. For a given choice of target mean return $\mu$, choose the portfolio $\theta$ to

$$
\operatorname{Min}\left\{\theta^{T} \sum \theta \mid A^{T} \theta=B\right\}
$$

where $A=(\mu \overline{1})$ and $B=\left(\begin{array}{l}\mu_{p} \\ C_{0}\end{array}\right)$.

Applying Lagrangian multipliers to the convex optimisation (minimisation) problem is subject to linear constraints

$$
L\left(\theta, \lambda_{1}, \lambda_{2}\right)=\frac{1}{2} \theta^{T} \sum \theta+\lambda_{1}\left(\mu_{0}-\theta^{T} \mu\right)+\lambda_{2}\left(1-\theta^{T} \overline{1}\right)
$$

Deriving the first-order conditions

$$
\begin{aligned}
& \frac{\partial L}{\partial \theta}=0=\sum \theta-\lambda_{1} \mu-\lambda_{2} \overline{1} \\
& \frac{\partial L}{\partial \lambda_{1}}=0=\mu_{0}-\theta^{T} \mu \\
& \frac{\partial L}{\partial \lambda_{2}}=0=1-\theta^{T} \overline{1}
\end{aligned}
$$

Solve for $\theta$ in terms of $\lambda_{1}, \lambda_{2}$ yields $\theta_{0}=\lambda_{1} \sum^{-1} \mu+\lambda_{2} \sum^{-1} \overline{1}$ and Solving for $\lambda_{1}, \lambda_{2}$ by substituting for $\theta$

$$
\begin{gathered}
\mu_{0}=\theta_{0}{ }^{T} \mu=\lambda_{1}\left(\mu^{T} \sum^{-1} \mu\right)+\lambda_{2}\left(\mu^{T} \sum^{-1}{ }^{-}\right) \\
1=\theta_{0}{ }^{T} 1=\lambda_{1}\left(\mu^{T} \sum^{-1} \frac{1}{1}\right)+\lambda_{2}\left(1^{T} \sum^{-1} \frac{1}{1}\right) \\
{\left[\begin{array}{l}
\mu_{0} \\
1
\end{array}\right]=\left[\begin{array}{ll}
a & b \\
b & c
\end{array}\right]\left[\begin{array}{l}
\lambda_{1} \\
\lambda_{2}
\end{array}\right]}
\end{gathered}
$$

where $a=\mu^{T} \Sigma^{-1} \mu, \quad b=\mu^{T} \Sigma^{-1} \overline{1}=\overline{1} \Sigma^{-1} \mu, c=\overline{1} \Sigma^{-1} \overline{1} \quad$ and $d=a c-b^{2}$. The parameters of $a, b, c$ and $d$ in Equation are positive. The assumption is that the covariance matrix $\Sigma$ is positive definite, the inverse matrix $\Sigma^{-1}$ is also positive definite. This means that $x^{T} \Sigma^{-1} x>0$ for all nonzero $(N \times 1)$-vectors $x$, so it is clear that $a>0, c>0$.

The second constraint is the expected return maximisation, for a given choice of target return variance $\sigma_{p}^{2}$, choose the portfolio $\theta$ to

$$
\begin{array}{ll}
\text { Max } & E\left(R_{p}\right)=\theta^{T} \mu \\
\text { subject to } & \theta^{T} \stackrel{a}{ } \theta=\sigma_{p}^{2} \\
& \theta^{T} \overline{1}=1
\end{array}
$$

solving using Lagrange application equation applied in Equation (7), the maximum expected return in the portfolio is obtained as

$$
\mu_{p}=\frac{b}{c} C_{0} \pm \sqrt{\frac{d}{c} \sigma_{p}}
$$

Minimum variance and efficient frontier on the portfolio are obtained as

$$
\begin{gathered}
\sigma_{p}=\frac{1}{d}\left(\begin{array}{ll}
\mu_{p} & C_{0}
\end{array}\right)\left(\begin{array}{cc}
c & -b \\
-b & a
\end{array}\right)\left(\begin{array}{l}
\mu_{p} \\
C_{0}
\end{array}\right)=\frac{1}{d}\left(c \mu_{p}^{2}-2 C_{0} \mu_{p}+a C_{0}^{2}\right) \\
\theta_{E F}=\frac{1}{d} \sum^{-1}\left(\left(a \overline{1}-b \mu_{p}\right) C_{0}+\left(c \mu_{p}-b \overline{1}\right) \mu_{p}\right)
\end{gathered}
$$

The importance of this model is to enable the investor to be aware of the amount that must be invested in the single asset to achieve the expected return and risk on the efficient frontier. The minimum variance for the investor to choose from in the efficient frontier of the portfolio is obtained as

$$
\begin{aligned}
\sigma_{m v}{ }^{2}=\theta^{T} \Sigma \theta & =\frac{C_{0}}{c}\left(\Sigma^{-1} \overline{1}\right)^{T} \Sigma \frac{C_{0}}{c} \Sigma^{-1} \overline{1} \\
& =\left(\frac{C_{0}}{c}\right)^{2}{ }^{-T} \Sigma^{-1} \overline{1}=\left(\frac{C_{0}}{c}\right)^{2} c=\frac{C_{0}}{c}
\end{aligned}
$$

and the minimum variance for the expected return is as

$$
\mu_{m v}=\mu^{T} \theta=\mu^{T} \Sigma^{-1} \frac{C_{0}}{c}=b \frac{C_{0}}{c}=\frac{b}{c} C_{0}
$$

\subsubsection{Value at Risk Efficient Frontier Portfolio Problem}

The $\operatorname{VaR}$ at level $1-\alpha$ of a portfolio $\left(V_{a} R_{\alpha}\right)$ is defined as and $P\left(R_{p} \leq-V a R_{\alpha}\right)=\alpha$ indicate the minimum amount an investor can lose with a confidence interval of $1-\alpha$. The bigger the $\operatorname{VaR}$ at some confidence level, the riskier the portfolio is. So, an investor who is extreme risk averse will prefer an extreme low $\operatorname{VaR}$. If $\operatorname{VaR}_{\alpha}=C_{0}$ where $\alpha$ is the shortfall probability, then the $V a R$ definition becomes the shortfall constraint in $\operatorname{Max}\left\{E\left(C_{0}+R_{p}\right) \mid P\left(C_{0}+R_{p} \leq 0\right) \leq \alpha\right\}$. A shortfall constraint is a special case of a $\operatorname{VaR}$ constraint. Value at Risk is the new risk measure, instead of standard deviation, a new efficient frontier can be calculated, just as it is done in the mean-standard deviation framework. The efficient frontier gives the highest expected return for some given Value at Risk, or the minimum $V a R$ for a fixed mean. The assumption is that the returns are elliptically distributed as shown in Figure 1. When the elliptical assumption is made, the Value at Risk is defined as Equation (15). 


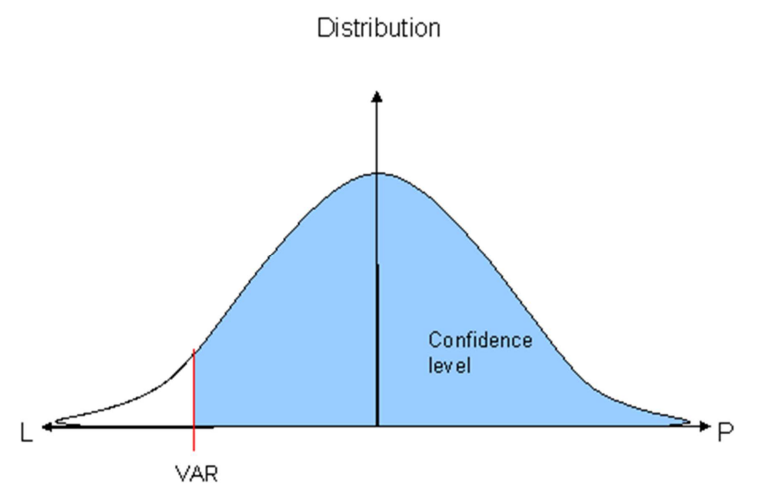

Figure 1. Definition of Value at Risk.

$$
\begin{aligned}
& P\left(R_{p} \leq-V a R_{\alpha}\right)=\alpha \\
\Rightarrow & P\left(\frac{R_{p}-\mu_{p}}{\omega_{p}} \leq \frac{-V a R-\mu_{p}}{\omega_{p}}\right)=\alpha \\
\Rightarrow & \frac{-V a R-\mu_{p}}{\omega_{p}}=k_{\alpha} \Rightarrow V a R=-\mu_{p}-k_{\alpha} \omega_{p}
\end{aligned}
$$

From elliptical distribution $\mu_{p} \geq-C_{0}-Z_{\alpha} \sigma_{p} \quad$ with $z_{\alpha} \equiv k_{\alpha} \omega_{p} / \sigma_{p}$.

Hence, VaR can be written as if $z_{\alpha}$ equation is substituted into Equation (17)

$$
\operatorname{VaR}=-\mu_{p}-z_{\alpha} \sigma_{p}
$$

\subsubsection{Portfolio Optimization of Telser VaR's Model Problem}

An Optimal Telser portfolio is defined as the portfolio that maximises the expected return while satisfying a VaR constraint [4]. Telser portfolio is defined when the VaR is equal to the initial capital the investor will invest $\left(\operatorname{VaR}=C_{0}\right)$. So, the Telser problem is

$$
\operatorname{Max}\left\{\mu_{p} \mid \begin{array}{l}
\mid \begin{array}{l}
V a R_{\alpha} \leq V a R_{c} \\
1^{T} \theta=C_{0} \\
\mu_{p}=\mu^{T} \theta
\end{array}
\end{array}\right\}
$$

where $\operatorname{VaR}_{c}$ is the maximum VaR of the portfolio allowed. When the returns are distributed elliptically, the first constraint is expressed as

$$
\begin{aligned}
& \operatorname{VaR}_{\alpha} \leq \operatorname{VaR}_{c} \Leftrightarrow \operatorname{VaR}_{c} \geq \operatorname{VaR}_{\alpha}=-\mu_{p}-z_{\alpha} \sigma_{p} \\
& \Rightarrow \mu_{p} \geq-\operatorname{VaR}_{c}-z_{\alpha} \sigma_{p}
\end{aligned}
$$

So, the portfolio optimisation problem is transformed into

$$
\operatorname{Max}\left\{\begin{array}{l}
\mu_{p} \\
\begin{array}{l}
\mu_{p} \geq-V a R_{c}-z_{\alpha} \sigma_{p} \\
1^{T} \theta=C_{0} \\
\mu_{p}=\mu^{T} \theta \\
\sigma_{p}{ }^{2}=\theta^{T} \Sigma \theta
\end{array}
\end{array}\right\}
$$

Since, the maximum allowed Value at Risk ( $\left.V a R_{c}\right)$ is equal to the starting capital, implies that $V a R_{c}=C_{0}$. The optimal point using the mean- $V a R$ efficient frontier with $V a R_{\alpha}=V a R_{c}$ yields

$$
V a R_{c}=-\mu_{p}-z_{\alpha} \sqrt{\frac{1}{d}\left(c \mu_{p}^{2}-2 b C_{0} \mu_{p}+a C_{0}^{2}\right)}
$$

Solving for $\mu_{p}$ results in

$$
\mu_{o p t}=\frac{b z_{\alpha}^{2} C_{0}+d V a R_{c}-z_{\alpha} \sqrt{d\left(\left(a-z_{\alpha}^{2}\right) C_{0}^{2}+2 b V a R_{c} C_{0}+c V a R_{c}^{2}\right)}}{c z_{\alpha}^{2}-d}
$$

the corresponding standard deviation is

$$
\begin{aligned}
\sigma_{o p t} & =\left(\frac{-V a R_{c}-\mu_{o p t}}{z_{\alpha}}\right) \\
& =\frac{z_{\alpha}\left(b C_{0}+c V a R_{c}\right)-\sqrt{d\left(\left(a-z_{\alpha}{ }^{2}\right) C_{0}{ }^{2}+2 b V a R_{c} C_{0}+c V a R_{c}^{2}\right)}}{d-c z_{\alpha}{ }^{2}}
\end{aligned}
$$

and the Value at Risk equals $V a R_{c}$. The optimal asset allocation $\theta_{o p t}$ is found by using the fact that the optimal portfolio lies on the efficient frontier as derived by Markowitz theory.

$$
\theta_{o p t}=\frac{1}{d} \Sigma^{-1}\left(\left(c \mu_{p}-b \overline{1}\right) \mu_{o p t}+(a \overline{1}-b \mu) C_{0}\right)
$$

\subsubsection{Telser Risk-Free Asset Problem Under the VaR}

If risk-free asset is added, the efficient frontier changes into the Capital Market Line (CML) [4]. The optimal Telser portfolio with risk-free asset is the portfolio where maximum return is gained by the investor, while satisfying the $\operatorname{VaR}$ -constraint is shown as Equation (25)

$$
\mu_{o p t}=\frac{-\delta V a R_{c}+C_{0} z_{\alpha} \mu_{f}}{z_{\alpha}+\delta}
$$

and the standard deviation is

$$
\sigma_{o p t}=\frac{\mu_{o p t}+V a R_{c}}{-z_{\alpha}}=-\frac{C_{0} \mu_{f}+V a R_{c}}{z_{\alpha}+\delta}
$$

The optimal allocation consists of a combination the market portfolio and the risk-free asset. Suppose an investor's proportion of fraction, $\Theta_{m}$, is invested in the market portfolio and a proportion of fraction, $\Theta_{f}$, is invested in the risk-free asset, the two fractions sum to one. Because the returns on the risk-free asset have no standard deviation, the portfolio standard deviation of the optimal portfolio is given by:

$$
\sigma_{o p t}=\sqrt{\Theta_{m}{ }^{2} \sigma_{m}{ }^{2}+\Theta_{f}^{2} \cdot 0}=\Theta_{m} \sigma_{m}
$$

where $\sigma_{m}$ is the standard deviation in the market portfolio, derived in the Markowitz theory. So, the fraction invested in this market portfolio is 


$$
\begin{aligned}
\Theta_{m}=\frac{\sigma_{o p t}}{\sigma m} & =\frac{\frac{-C_{0} \mu_{f}+V a R_{c}}{z_{\alpha}+\delta}}{\frac{\delta}{b-c \mu_{f}} C_{0}} \\
& =\frac{\left(C_{0} \mu_{f}+V a R_{c}\right)\left(c \mu_{f}-b\right)}{\delta\left(z_{\alpha}+\delta\right) C_{0}}
\end{aligned}
$$

The fraction invested in the risk-free asset is

$$
\Theta_{f}=1-\Theta_{m}=\frac{\left(a-b \mu_{f}+\delta z_{\alpha}\right) C_{0}+V a R_{c}\left(b-c \mu_{f}\right)}{\delta\left(z_{\alpha}+\delta\right) C_{0}}
$$

where $\delta=\sqrt{c \mu_{f}^{2}-2 b \mu_{f}+a}$ hence, the optimal allocation with risk-free asset becomes

$$
\begin{aligned}
\theta_{o p t} & \equiv\left(\begin{array}{l}
\theta_{1} \\
\frac{\theta_{N}}{\theta_{f}}
\end{array}\right)=\left(\frac{\Theta_{m} \theta_{m}}{\Theta_{f} C_{0}}\right) \\
& =\left(\frac{\frac{V a R_{c}+\mu_{f} C_{0}}{\delta\left(z_{\alpha}+\delta\right)} \Sigma^{-1}\left(\mu_{f} \overline{1}-\mu\right)}{\frac{\left(a-b \mu_{f}+z_{\alpha}\right) C_{0}+V a R_{c}\left(b-c \mu_{f}\right)}{\delta\left(z_{\alpha}+\delta\right)}}\right)
\end{aligned}
$$

\section{Results and Discussions}

\subsection{Preliminary Analysis}

Table 2 shows the descriptive statistics of the stocks considered in the study. As observed, it is apparent that in Financial Stocks Index, SIC stock has 5.504 as the highest expected returns followed by GCB, EBG and $\mathrm{CAL}$ whiles SCB made the least expected returns of 1.350 analysed over the period. For Composite Index, TOTAL stock has the highest expected return of 6.312 whiles GOIL and UNIL made expected returns of 2.1688 and 2.4058. AYRTN and ALW stocks were among the securities that made the least expected return of 0.4618 and 0.1594 respectively.

Also, it can be observed that, the variable from which the sample was extracted does not follow a normal distribution because the computed p-values obtained from the Jarque-Bera and Shapiro-Wilk test as 0.0001 is lower than the significance level alpha $=0.05$. Apart from SCB, GGBL and PZC that have negative skewness indicating an increased in probability at the higher quantiles (heavy left tails) which is close to student-t distribution with degree 6 . The remaining equity have positive skewness depicting increased in probability at the higher quantiles (heavy right tails).

Table 2. Descriptive Statistics of Selected Stocks in GSE.

\begin{tabular}{llllll}
\hline Stocks & Mean & $\begin{array}{l}\text { Standard } \\
\text { Deviation }\end{array}$ & $\begin{array}{l}\text { Jarque } \\
\text { Bera }\end{array}$ & $\begin{array}{l}\text { Shapiro } \\
\text { Wilk }\end{array}$ & $\begin{array}{l}\text { Skewne } \\
\text { ss }\end{array}$ \\
\hline CAL & 2.085 & 8.038 & 0.0001 & 0.0001 & 1.708 \\
EBG & 2.810 & 7.322 & 0.0001 & 0.0001 & 2.152 \\
ETI & 1.812 & 8.822 & 0.0001 & 0.0001 & 1.328 \\
\hline
\end{tabular}

\begin{tabular}{llllll}
\hline Stocks & Mean & $\begin{array}{l}\text { Standard } \\
\text { Deviation }\end{array}$ & $\begin{array}{l}\text { Jarque } \\
\text { Bera }\end{array}$ & $\begin{array}{l}\text { Shapiro } \\
\text { Wilk }\end{array}$ & $\begin{array}{l}\text { Skewne } \\
\text { ss }\end{array}$ \\
\hline GCB & 2.861 & 8.947 & 0.0001 & 0.0001 & 3.129 \\
HFC & 1.586 & 4.691 & 0.0001 & 0.0001 & 3.736 \\
SCB & 1.350 & 8.353 & 0.0001 & 0.0001 & -3.726 \\
SIC & 5.504 & 15.379 & 0.0001 & 0.0001 & 3.044 \\
ALW & 0.1594 & 9.171 & 0.0001 & 0.0001 & 0.0695 \\
AYRTN & 0.4618 & 2.548 & 0.0001 & 0.0001 & 1.7303 \\
GOIL & 2.1688 & 7.776 & 0.0001 & 0.0001 & 2.3003 \\
FML & 0.8236 & 4.461 & 0.0001 & 0.0001 & 4.4462 \\
GGBL & 0.8542 & 5.618 & 0.0001 & 0.0001 & -0.8555 \\
PZC & 1.5642 & 9.660 & 0.0001 & 0.0001 & -0.4618 \\
TOTAL & 6.3120 & 15.048 & 0.0001 & 0.0001 & 3.3918 \\
UNIL & 2.4058 & 9.245 & 0.0001 & 0.0001 & 1.7918 \\
\hline
\end{tabular}

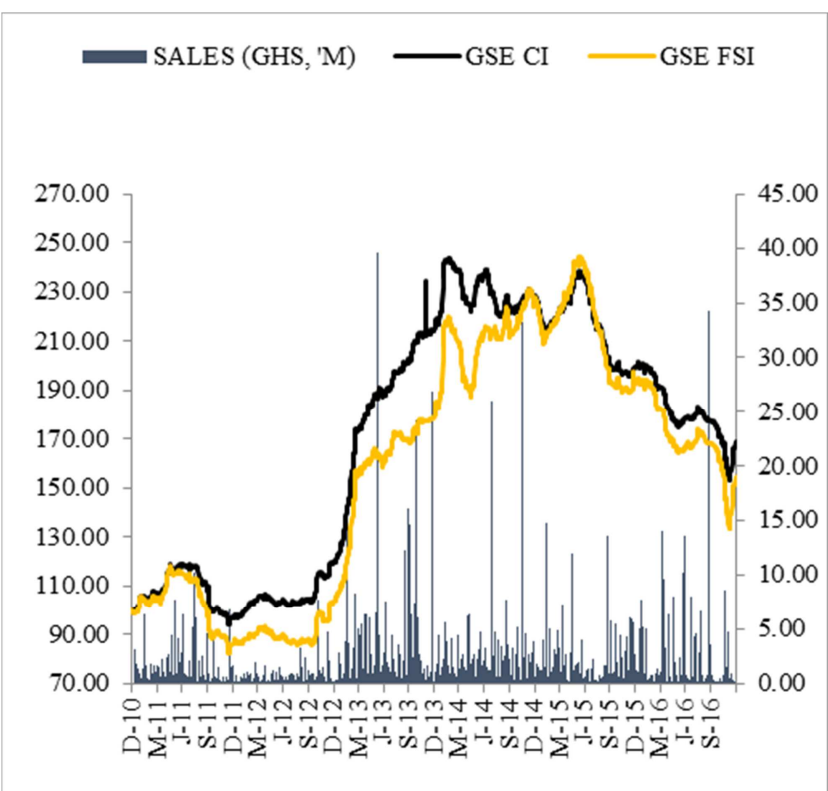

Figure 2. GSE All-Shares Index Evolution (Source: GSE, 2017).

Time series plot of the indexes exhibit a progressive rise in returns and the volatility of stock performance are shown in Figure 2. As observed from the year 2010, change in price of stock was stable until January, 2013 where change in price was marginally volatile for all stocks trading and that continues to 2017. Both composite index and financial stock index had the same movement in price change trend in the stock price.

\subsection{Performance of Stocks on Ghana Stock Exchange}

Beta is a quantitative measure of the volatility of a given stock, relative to the overall market. It measures systematic risk of a company [5]. From Table 3 it is evident that CAL (1.01) and EBG (1.73) have their beta value greater than the market beta rate of one, meaning these stocks were aggressive. GCB (0.79) and SCB (0.74) have their beta value less than one of the standard market beta measured but not valued at negative. Equity such as ETI (-2.81), HFC (-3.27) and SIC $(-3.06)$ have negative beta values which is extremely less than one, implying, these stocks play a defensive mechanism in the stock market. That is, considering the stocks under FSI, 30\% 
were aggressive, $30 \%$ were defensive and the remaining $40 \%$ were inversely moving towards to the market return. Also, financial stock index such as ETI (1.55), HFC (0.41) and SIC (0.16) have their Jensen alpha value greater than the market return $(\mathrm{Rm})$ of zero, implying that the equities are over performing on the GSE. However, equity such as GCB (-0.02), EBG (-0.09), CAL (-0.15) and SCB (-1.13) are under performing in the market because the estimated Jensen alpha value is negative and is by far less than zero which mean their estimated alpha value is less than their market returns.

Table 3. Stock's Performance Relative to the Market Performance (FSI).

\begin{tabular}{lllllll}
\hline Stocks & Market Return $($ Rm) & Rt & Beta & Sharpe Ratio & Jensen Alpha & Performance Ranking \\
\hline ETI & -0.28 & 0.80 & -2.81 & 0.272 & 1.55 & $1^{\text {st }}$ \\
HFC & -0.31 & 1.02 & -3.27 & 0.447 & 0.41 & 0.16 \\
SIC & -0.29 & 0.91 & -3.06 & 0.250 & -0.02 & -0.09 \\
GCB & 1.33 & 1.05 & 0.79 & 0.399 & -0.15 & $3^{\text {rd }}$ \\
EBG & 1.08 & 1.87 & 1.73 & 0.398 & $4^{\text {th }}$ \\
CAL & 0.79 & 0.80 & 1.01 & 0.308 & -1.31 & $6^{\text {th }}$ \\
SCB & 1.20 & 0.89 & 0.74 & 0.314 & $7^{\text {th }}$ & \\
\hline
\end{tabular}

With regards to the Composite Index (CI), Table 4 shows that beta value for ALW (1.00), AYRTN (1.50) and GOIL (1.20) is greater than one. GGBL $(0.40)$ had its beta value slightly lower than one but in the case of TOTAL (-0.57), FML (-4.24), PZC (-4.70) and UNIL (-0.60) have a negative beta value extremely lesser than standard market beta value of one. Per the estimated beta, ALW, AYRTN and GOIL stocks are classified as the aggressive stocks whilst TOTAL, FML, PZC and UNIL stocks performance moves inversely to the market return. GGBL had a defensive stock mechanism with their performance sandwich between Aggressiveness and inversely moving towards the market return. That is, considering the stocks under CI, $40 \%$ were aggressive, $20 \%$ were defensive and the remaining $40 \%$ were inversely moving towards to the market return. Also, TOTAL, FML, UNIL and GOIL from the composite index have Jensen alpha value greater than zero categorising the equities as over performing on the GSE. However, AYRTN (-0.03), PZC (-0.06), ALW (-0.06), and GGBL (-1.20) indicated negative alpha values classifying the above listed stock as underperforming on the GSE.

Table 4. Stock's Performance Relative to the Market Performance (CI).

\begin{tabular}{lllllll}
\hline Stocks & Market Return $($ Rm) & Rt & Beta & Sharpe Ratio & Jensen Alpha & Performance Ranking \\
\hline TOTAL & -4.23 & 2.41 & -0.57 & 0.017 & 8.74 & $1^{\text {st }}$ \\
FML & 2.40 & 0.00 & -4.24 & 0.181 & 2.04 & 2.03 \\
UNIL & -4.20 & 2.40 & -0.60 & 0.278 & 0.07 & $2^{\text {nd }}$ \\
GOIL & 1.90 & 2.20 & 1.20 & 0.184 & -0.03 & -0.06 \\
AYRTN & 0.30 & 0.50 & 1.50 & 0.152 & -0.06 & $4^{\text {th }}$ \\
PZC & -0.30 & 1.60 & -4.70 & 0.162 & $5^{\text {th }}$ & $6^{\text {th }}$ \\
ALW & 0.20 & 0.20 & 1.00 & 0.419 & $8^{\text {th }}$ \\
GGBL & 1.90 & 0.90 & 0.40 & 0.230 & & -1.20 \\
\hline
\end{tabular}

This implies that, approximately $43 \%$ of the equities are over performing and $57 \%$ are underperforming on the GSE with regards to the Financial Stock Index (see Table 3). However, in the Composite Index, $50 \%$ of the equities are over performing and the other half, underperforming (see Table 4). This analysis confirms the conclusion to the [6], that no investor is expected to consistently outperform or beat the market return. However, this assertion contradicts the findings of [3] position, that stock returns are often found at random, and investors who are not capable of constantly earning an excess return because market prices often deviate from their intrinsic value and dynamism in market capitalisation.

\subsection{Portfolio Optimization Using Value at Risk}

Assuming the confidence level for one day VaR is $95 \%$, hence $\alpha=0.05$. Suppose the investor has a Value at Risk limit of $5 \%$, then $\mathrm{VaR}=0.5$. This means that the probability that the investor loses more than $5 \%$ of his money is less than $\alpha=0.5$.

The optimal Telser mean, standard deviation and allocation are given in the Table 5. From Table 5, the asset allocation for the minimum VaR portfolio ( $\left.\theta_{m v r}\right)$ showed a marginal diversification in other stocks but greater portion was invested in HFC taking a swipe of $46.60 \%$ and $54.40 \%$ in the remaining securities. However, it is observed that the value for the VaR limit at $10 \%\left(\operatorname{VaR}_{c}=0.1\right)$ is quite high because the optimal portfolio invests much in EBG (0.394), SIC (0.315) and GCB $(0.245)$ and goes short in the other securities to generate the amount invested in the three assets mentioned. Similar instances occurred in $\operatorname{VaR}_{c}=0.05,0.02,0.01$.

To invest in Financial Stock Index, if an investor, on the basis of Bank of Ghana's $\alpha=0.05$, is willing to incur loss of $5 \%$ at a Minimum Variance implies at $95 \%$ of 30 -day VaR is 0.068 , then it means that the investor held the position for 30-days and should not be expecting to lose more than 0.068 from the portfolio expected return of 0.730 at risk factor of 3.756. For investor who wants to make optimum returns of 30-days VaR at the probability level of (confidence level): $90 \%, 95 \%, 98 \%$ and $99 \%$ produce respective portfolio expected return of: $1.599,3.080,3.933$ and 9.672 and portfolio risk of: $0.127,0.217,0.280$ and 0.302 to have a position held not to lose more than: $0.058,0.058,0.065$ and 0.103 . However, considering more risk averse investor taking a lowered VaR limit of 0.05, 0.02 and 0.01 (confidence level of standard deviation for the normal distribution: 1.645, 2.054 and 2.326) is advisable. 
Table 5. Minimum Value at Risk portfolio and Optimal Telser Portfolio (FSI).

\begin{tabular}{llllll}
\hline \multirow{2}{*}{ Stocks } & \multicolumn{1}{l}{$\begin{array}{c}\theta_{\operatorname{mr}} \\
\left(\operatorname{VaR}_{\alpha}=0.05\right)\end{array}$} & $\operatorname{VaR}_{c}=0.1$ & $\operatorname{VaR}_{c}=0.05$ & $\operatorname{VaR}_{c}=0.02$ & $\operatorname{VaR}_{c}=0.01$ \\
\hline CAL & 0.049 & -0.409 & -0.368 & -0.340 & -0.330 \\
EBG & 0.092 & 0.394 & 0.331 & 0.290 & 0.275 \\
ETI & 0.095 & -0.220 & -0.209 & -0.201 & -0.199 \\
GCB & 0.105 & 0.245 & 0.198 & 0.167 & 0.156 \\
HFC & 0.466 & -1.256 & -1.179 & -1.127 & -1.109 \\
SCB & 0.125 & -0.360 & -0.337 & -0.321 & -0.315 \\
SIC & 0.043 & 0.315 & 0.270 & 0.240 & 0.229 \\
$\mu_{T}$ & 0.730 & 1.599 & 3.08 & 3.933 & 6.672 \\
$\operatorname{VaR}_{\text {hin }}$ & 0.068 & 0.058 & 0.058 & 0.065 & 0.103 \\
$\sigma_{T}$ & 3.756 & 0.127 & 0.217 & 0.280 & 0.302 \\
\hline
\end{tabular}

Using Equation (21), the mean-VaR efficient frontier for the Financial Stock Index (FSI) is given as

$$
V a R_{\alpha}=-\mu_{p}+1.96 \sqrt{-0.10335 \mu_{p}^{2}+0.36879 \mu_{p}-0.51593}
$$

However, in Table 6, the composite index displays investors interest in AYRTN. There was no diversification in the portfolio because $67.30 \%$ of investors invested in AYRTN and only $32.70 \%$ in the remaining securities. In the composite index, AYRTN received the greater investment whilst the other seven securities go short with amount invested in them equals the amount invested in AYRTN alone.

For an investor to invest in Composite Index, that is when the investor is willing to incur loss of $5 \%(\alpha=0.05)$, at a Minimum Variance implies that at $95 \%$ of 30 -day VaR is 0.034 , then it means that the investor held the position for 30-days and should not be expecting to lose more than 0.034 from the portfolio expected return of 0.703 at risk factor of 0.170 . For investor who wants to make optimum returns of 30-days VaR at the probability level of (confidence level): $90 \%, 95 \%, 98 \%$ and $99 \%$ produce respective portfolio expected return of: $0.942,2.521,4.824$ and 6.475 and portfolio risk of: $0.982,0.323,0.307$ and 0.302 to have a position held not to lose more than: $0.031,0.032,0.041$ and 0.048 .

Table 6. Minimum Value at Risk portfolio and Optimal Telser Portfolio (CI).

\begin{tabular}{|c|c|c|c|c|c|}
\hline \multirow{2}{*}{ Stocks } & \multirow{2}{*}{$\begin{array}{c}\theta_{m r r} \\
\left(V a R_{\alpha}=0.05\right)\end{array}$} & \multicolumn{4}{|c|}{ Optimal Telser } \\
\hline & & $V a R_{c}=0.1$ & $V a R_{c}=0.05$ & $V a R_{c}=0.1$ & $V a R_{c}=0.01$ \\
\hline ALW & 0.047 & 0.058 & -0.282 & -0.282 & -0.282 \\
\hline GOIL & 0.025 & 0.113 & 0.195 & 0.195 & 0.195 \\
\hline FML & 0.160 & 0.083 & -1.432 & -1.432 & -1.432 \\
\hline GGBL & 0.087 & 0.010 & -0.927 & -0.927 & -0.927 \\
\hline TOTAL & 0.048 & 0.153 & 0.096 & 0.096 & 0.096 \\
\hline UNIL & 0.059 & 0.130 & -0.120 & -0.120 & -0.120 \\
\hline$\mu_{T}$ & 0.703 & 0.942 & 2.521 & 4.824 & 6.475 \\
\hline$V a R_{\min }$ & 0.034 & 0.032 & 0.0315 & 0.041 & 0.048 \\
\hline$\sigma_{T}$ & 0.170 & 0.982 & 0.323 & 0.307 & 0.302 \\
\hline
\end{tabular}

Using Equation (21), the mean-VaR efficient frontier for the Composite Index (CI) is given as:

$$
V a R_{\alpha}=-\mu_{p}+1.96 \sqrt{0.05379 \mu_{p}^{2}-0.08051 \mu_{p}+0.06982}
$$

In Financial Stock Index, investors investment policy reduces gradually for more risk averse but in the composite index more risk averse investors diverted their investment policy to GOIL and PZC. Even though, the Sharpe ratio of PZC (0.162) and GOIL (0.278) are low (see Table 3), investors can still invest, hoping that the market return pick-up because at point shares will be low unlike GCB (0.399) and EBG (0.447) with high Sharpe ratio will have their share price higher than those low Sharpe ratios. However, high Sharpe ratio imposes confidence in the investors comparing their minimum variance for both low and high Sharpe ratios for investment decision.

\subsection{Optimal Portfolio with Risk-Free}

In a situation where an investor wants to combine risky asset and risk-free asset at risk-free asset rate of return of $\mu_{f}=0.2$, then using Equation (25), the efficient frontier changes into Capital Market Line (CML) which means that Mean-VaR space for FSI and CI, is shown in Equations (33) and (34) respectively.

$$
\mu_{p f s i}=-0.007 \operatorname{VaR}_{\alpha}+0.0136
$$




$$
\mu_{p c i}=-0.007 V a R_{\alpha}+0.0137
$$

Applying VaR model, the expected return calculated for the Market Portfolio (FSI) is $\mu_{m}=3.08$ and the $\operatorname{VaR}_{m}=0.0576$, which mean the expected loss for the Market Portfolio at confidence level of $95 \%$ will not exceed 0.0576 . This is like investors investing in Composite Index (CI) with its expected return of $\mu_{m}=2.9758$ and $\mathrm{VaR}_{m}=0.0427$. The portfolio allocation for the optimal Telser portfolio with risk-free asset for FSI and CI is shown in Tables 7 and 8 respectively.

With regards to the optimal Telser portfolio with risk-free asset for FSI shown in Table 7, it is observed that the value for $\mathrm{VaR}$ is quite high, because the optimal portfolio invests in CAL stock and the rest of the securities goes short to generate the amount invested in CAL. But the investor who is risk averse will go for lower VaR and risk-free investment. From Table 7, a risk averse investor with the lower VaR limit of $\operatorname{VaR}_{c}=0.01$ makes higher expected market return $\left(\mu_{m T}\right.$ $=0.011)$ with the least market variance $\left(\sigma_{m T}=0.011\right)$ but investor with higher VaR limit of $V a R_{c}=0.1$ makes the lowest market return ( $\left.\mu_{m T}=-0.009\right)$ with high market variance ( $\sigma_{m T}$ $=0.046)$ of the portfolio.

Table 7. Optimal Telser Portfolio with Risk-Free (FSI).

\begin{tabular}{lllll}
\hline Stock & $V a R_{c}=0.1$ & $V a R_{c}=0.05$ & $V a R_{c}=0.02$ & $V a R_{c}=0.01$ \\
\hline CAL & 0.004 & 0.002 & 0.001 & 0.001 \\
EBG & -0.016 & -0.009 & -0.005 & -0.004 \\
ETI & -0.004 & -0.002 & -0.001 & -0.001 \\
GCB & -0.014 & -0.008 & -0.005 & -0.003 \\
HFC & -0.017 & -0.010 & -0.005 & -0.004 \\
SCB & -0.004 & -0.002 & -0.001 & -0.001 \\
SIC & -0.010 & -0.006 & -0.003 & -0.002 \\
$\theta_{R f}$ & 1.010 & 1.006 & 1.003 & 1.002 \\
$\mu_{T}$ & -0.009 & 0.002 & 0.009 & 0.011 \\
$\sigma_{T}$ & 0.046 & 0.027 & 0.015 & 0.011 \\
\hline
\end{tabular}

With regards to the optimal Telser portfolio with risk-free asset for CI shown in Table 8, GOIL asset was considered worth investing into. As the VaR limit ( $\left.\operatorname{VaR}_{c}\right)$ decreases, the market variance and the expected return of the portfolio also increases. Hence, an investor can borrow at risk-free rate (because portfolio risk-free asset decreases). When $\operatorname{VaR}_{c}=0.1$ then 0.047 estimated standard deviation will isolate $10 \%$ of the area of distribution in the lower tail of the normal curve, by providing $90 \%$ confidence in the estimate. In this case, an investor can lend at the risk-free rate and become better off. For the more risk averse investor, the lower the VaR considered, the lower the expected return. The standard deviation gets also lower and the amount borrowed at the risk-free rate becomes less. At estimated VaR alpha value of 0.05 to 0.01 , the investor lends at the risk-free rate. This contradict the findings of [4] whose stipulation is that the lower the VaR limit, the lower the expected return and the variance.
Table 8. Optimal Telser Portfolio with Risk-free (CI).

\begin{tabular}{lllll}
\hline Stock & $V_{c}=0.1$ & $V_{c}=0.05$ & $V_{c} a R_{c}=0.02$ & $V_{c}=0.01$ \\
\hline ALW & -0.005 & -0.003 & -0.002 & -0.001 \\
AYRTN & -0.044 & -0.026 & -0.014 & -0.010 \\
GOIL & -0.010 & -0.006 & -0.003 & 0.002 \\
FML & -0.008 & -0.005 & -0.003 & -0.002 \\
GGBL & -0.001 & -0.001 & 0.000 & 0.000 \\
PZC & 0.000 & 0.000 & 0.000 & 0.000 \\
TOTAL & -0.014 & -0.008 & -0.004 & -0.003 \\
UNIL & -0.012 & -0.007 & -0.004 & -0.003 \\
$\mu_{r f}$ & 1.015 & 1.009 & 1.005 & 1.004 \\
$\mu_{T}$ & -0.009 & 0.003 & 0.009 & 0.011 \\
$\sigma_{T}$ & 0.047 & 0.027 & 0.015 & 0.011 \\
\hline
\end{tabular}

\section{Conclusions}

The study was conducted to identify the performing stock as well as examine the portfolio optimisation with associated Value at Risk (VaR) for both Financial Stock Index (FSI) and Composite Index (CI) on the Ghana Stock Exchange. From the study, it is concluded that ETI, HFC, SIC for the Financial Stock Index (FSI), and TOTAL, FML, UNIL and GOIL for the Composite Index (CI) were identified as the over performing stocks on the Ghana Stock Exchange. That is, approximately $43 \%$ of the equities are over performing and $57 \%$ are underperforming on the GSE with regards to the FSI whilst it was $50-50 \%$ in the case of CI. Also, CAL, EBG, ALW, AYRTN, GOIL were identified as aggressive (Beta $>1)$; GCB, SCB, TOTAL, GGBL as defensive $($ Beta $<1)$ and ETI, HFC, SIC, FML, PZC, UNIL $($ Beta $<0)$ as inversely moving towards the market return. The optimal portfolio asset allocation, for the minimum $\mathrm{VaR}$ portfolio showed a marginal diversification in other stocks in the cases of FSI, but greater portion was invested in HFC taking the majority $46.60 \%$ and $54.40 \%$ in the remaining securities. However, it is observed that the value for the VaR limit $\left(\operatorname{VaR}_{c}=0.1\right.$, $0.05,0.02,0.01)$ was quite high because the optimal portfolio invests much in EBG, SIC and GCB, and goes short in the other securities to generate the amount invested in the three assets mentioned. However, the Composite Index displayed no indication of diversification in the portfolio because $67.30 \%$ of investors invested in AYRTN and only $32.70 \%$ in the remaining securities. With regards to the optimal Telser portfolio with risk-free asset, the value for VaR for FSI was quite high as the optimal portfolio invests more in CAL stock. In terms of the CI, GOIL asset was considered worth investing into, as the VaR limit decreased with increasing market variance and the expected return of the portfolio. The study recommends that further study should extend the approaches used by considering Conditional Value at Risk (CVaR) as the VaR measure does not give any information about potential losses in the worst cases. 


\section{References}

[1] Anon. (2004), "Output, the Stock Market and Interest Rates", Databank Brokerage Ltd., 9 pp.

[2] Das, S., Markowitz, H., Scheid, J. and Statman, M. (2010), "Portfolio optimization with mental accounts", Journal of Financial and Quantitative Analysis, Vol. 45, No. 2, pp. 311-334.

[3] Degutis, A., \& Novickyte, L. (2014), "The efficient market hypothesis: a critical review of literature and methodology", Ekonomika, Vol. 93, No. 2, pp. 7-23.

[4] Engels, M. (2004), Portfolio Optimisation: Beyond Markowitz, Conceptual and Practical Insights Leiden University, Netherlands, pp. 45-53.

[5] Fabozzi, F. J. and Francis, J. C. (1979), "Mutual fund systematic risk for bull and bear markets: an empirical examination", The Journal of Finance, Vol. 34, No. 5, pp. 1243-1250.

[6] Frimpong, J. M. and Oteng-Abayie E. F. (2007), "Market Returns and weak-form efficiency: The case of the Ghana Stock Exchange", Journal of Economics and Finance, Vol. 4, No. 3, pp. 88-96.

[7] Jarque, C. M. and Bera, A. K. (1987), “A test for normality of observations and regression residuals", International Statistical Review, Vol. 55, pp. 163-172.

[8] Karadag, D. T. (2008), "Portfolio Risk Calculation and

Stochastic Portfolio Optimisation by a Copula Based Approach", Working Paper, Economics WPA, Bagazici University, $102 \mathrm{pp}$.

[9] Konno, H. and Yamazaki, H. (1991), "Mean-absolute deviation portfolio optimization model and its applications to Tokyo stock market", Management science, Vol. 37, No. 5, pp. 519-531.

[10] Magnus, F. J., Fosu, E. and Oteng-Abayie, J. (2006), "Modelling and Forecasting Volatility of Returns on Ghana Stock Exchange Using Garch Models", Am. Journal of Applied Science, Vol. 3, No. 10, pp. 2042-2048.

[11] Markowitz, H. M. (1952), "Portfolio Selection", The Journal of Finance, Vol. 7, No. 1, pp. 77-91.

[12] Mensah, M., Awunyo-Vitor, E. and El Wilson, S. (2012), "Challenges and Prospects of the Ghana Stock Exchange", Developing Country Studies, Vol 2, No. 10, pp. 226-250.

[13] Perold, A. F. (1984), "Large-scale portfolio optimization", Management science, Vol. 30, No. 10, pp. 1143-1160.

[14] Quismorio, A. B. (2010), "The tail distribution of the Philippines stock price index", Up College of Business Administration, Discussion Papers, DP No. 1003, pp. 87-95.

[15] Sharpe, W. (1966), "Mutual Fund Performance", The Journal of Business, Vol. 39, No. 1, pp. 119-138.

[16] Wiah, E. N., Odoi, B. and Antwi, K. O. (2018), "Asset Portfolio Optimisation of Some Selected Equities Using Geometric Mean and Semi Variance", Ghana Journal of Technology, Vol. 2, No. 2, pp. 24-33. 